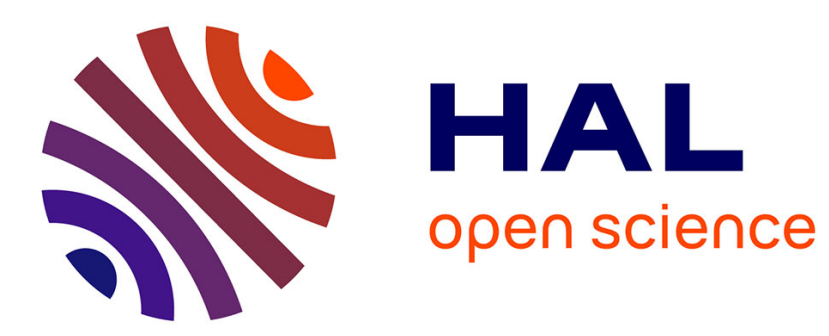

\title{
Mirage detection for electrochromic materials characterization. Application to iridium oxide films
}

\author{
V. Plichon, M. Petit
}

\section{To cite this version:}

V. Plichon, M. Petit. Mirage detection for electrochromic materials characterization. Application to iridium oxide films. Journal de Physique IV Proceedings, 1994, 04 (C7), pp.C7-429-C7-432. 10.1051/jp4:19947101 . jpa-00253153

\section{HAL Id: jpa-00253153 https://hal.science/jpa-00253153}

Submitted on 1 Jan 1994

HAL is a multi-disciplinary open access archive for the deposit and dissemination of scientific research documents, whether they are published or not. The documents may come from teaching and research institutions in France or abroad, or from public or private research centers.
L'archive ouverte pluridisciplinaire HAL, est destinée au dépôt et à la diffusion de documents scientifiques de niveau recherche, publiés ou non, émanant des établissements d'enseignement et de recherche français ou étrangers, des laboratoires publics ou privés. 


\title{
Mirage detection for electrochromic materials characterization. Application to iridium oxide films
}

\author{
V. Plichon and M.A. Petit \\ Laboratoire de Chimie et Electrochimie des Matériaux Moléculaires, UA 429 du CNRS, ESPCI, I0 rue \\ Vauquelin, 75231 Paris cedex 05, France
}

\begin{abstract}
The standing of electrochromic materials upon electrochemical cycling is a key problem in the development of electrochromic devices. The time stability of these materials depends strongly on the nature of the ionic species exchanged at the interface electrolytic solution/electrochromic material. In this paper we report that the so-called mirage effect may be used to characterize these ionic fluxes.
\end{abstract}

\section{INTRODUCTION}

Electrochromic materials for smart windows still suffer limitations on extended cycling. This generally does not come from the electron transfer which is fast and easy in such systems but from the fluxes of counterions entering or exiting the material during the electrochemical reaction. Since the size of these counterion may induce slight deformations of the lattice at each cycle, a good knowledge of the counterion fluxes is of prime importance for the characterization of electrochromic films. In this paper, we show using Sputtered Iridium Oxide Films (SIROFs) that mirage detection can give this information.

A Probe Beam Deflection (PBD) technique also called "mirage effect" was used in combination with Cyclic Voltametry (CV) to determine the nature of the ions which are exchanged between the solvent and the electrochromic material. The principle of the experiment may be briefly resumed as follows. When an electrochemical oxidation or reduction of an active film is carried out, ionic fluxes are produced through the solvent/film interface in order to maintain the electroneutrality. Such ionic fluxes generate a concentration gradient at the electrode surface and consequently a refractive index gradient. A laser beam tangential to the film surface is deflected according to these gradients. Monitoring the laser spot with a position detector allows to know the deflection direction and to conclude whether there has been a decrease or an increase of the refractive index at the electrode surface. In typical PBD experiments, a decreased (increased) refractive index is generally related to a decreased (increased) concentration of the electrolyte, i.e. counterions enter (exit) the film, $\mathrm{LiBF}_{4}$ excepted, as shown in the following diagram:

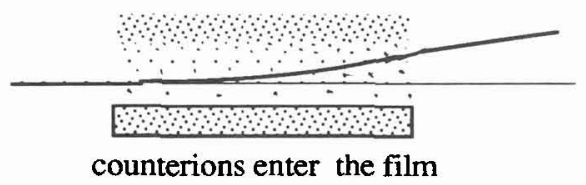

counterions enter the film

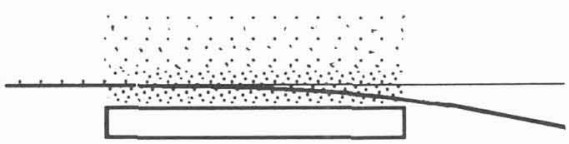

counterions exit the film 


\section{RESULTS AND DISCUSSION}

We have found that the electrochemical properties of SIROFs, such as current/potential and charge/potential curves are strongly dependent on the electrolytic solution $(1,2)$. Thus three types of voltamograms shown on Figure 1a, $2 \mathrm{a}$ and $3 \mathrm{a}$ can be obtained depending on the experimental conditions.

The voltamogram fig. 1a is typical of an irreversible oxidation reaction followed by a very slow reduction reaction during the reverse potential scan. It has been run in dry propylene carbonate containing $0.3 \mathrm{M} \mathrm{LiBF} 4$ as the electrolyte(1). The voltamogram 2 a shows a splitting of the voltametric peak into two well resolved peak systems, the reduction current being this time easily recorded. It has been obtained in neutral aqueous electrolyte (2) such as $\mathrm{LiCl}, \mathrm{LiClO}_{4}, \mathrm{LiCF}_{3} \mathrm{SO}_{3}, \mathrm{NaCl}, \mathrm{KCl}$...As for the voltamogram $3 \mathrm{a}$, it has been obtained either in aqueous $\mathrm{LiBF}_{4}$ solutions or in $\mathrm{pH}$-buffered aqueous solutions (acidic, neutral and basic). Its main feature is that the two voltametric peaks have merged into a capacitor-like response to a potential scan ("supercapacity" behavior (3)).

The question was to elucidate whether these changes of the shape of the voltamograms come from a modification of the electrochemical reaction (e.g. oxidation and reduction of the iridium oxide at different redox levels) or from another reason. In a forthcoming communication (1), we report using electrochemical investigations performed in propylene carbonate/water mixtures, that the redox reaction remains unchanged whatever the electrolytic solution and consequently cannot explain the water dependence. Thus, we found that only iridium (III) and (IV) oxides are the main species to consider. Therefore we propose that the changes of the voltamograms are due to changes in the nature of the counterions which are exchanged at the film/solution interface during the electrochemical reaction.

Combining CV and PBD by recording simultaneously current and mirage deflection, allows to determine for each voltametric peak (oxidation or reduction) the direction of the counterion flux and therefore, deduce whether the counterions are anions or cations. The anodic and cathodic parts of the voltamograms were recorded successively but with taking a break between them to restore the probed layer of the solution to homogeneity. This procedure leads to a more reliable backward signal.

In combination with Figure 1a, Figure $1 \mathrm{~b}$ shows that a cation could exit the film upon oxidation in dry LiBF4 propylene carbonate since $\mathrm{LiBF}_{4}$ decreases the refractive index of the solution (unusual case leading to a deflection in the opposite direction, as the one shown on the above diagram). This cation should be $\mathrm{Li}^{+}$since no other cations are available in the medium. However, the mirage deflection has an unusual high value which has not yet been clearly explained. During the voltamogram of Figure $2 \mathrm{a}$, mirage experiments represented in Figure $2 b$ show that the two peaks have counterions fluxes in opposite direction. Thus, an anion exchange (entering/exiting during oxidation/reduction) may be postulated for the system at the lowest potential while a cation exchange (exiting/entering during oxidation/reduction) is probable for the system at the highest potential. Finally, the last type of voltamogram shown in Figure $3 \mathrm{a}$ corresponds to a countercation $\left(\mathrm{H}^{+}\right)$flux in acidic aqeous media, a countercation $\left(\mathrm{Li}^{+}\right)$flux in neutral aqueous LiBF4 and a counteranion $\left(\mathrm{OH}^{-}\right)$flux in basic aqueous media according to Figures $3 \mathrm{~b}$ and $3 \mathrm{c}$.

These experiments show that the shape of a SIROF voltamogram is highly dependent on the electrolytic solution. This dependence is complex since both the electrochemical reaction and the nature of the counterion fluxes may be changed. Though further studies are needed, the PBD technique appears clearly as a useful tool for the characterization of the species exchanged at solid/liquid interfaces and in particular at the interface between electrolytic solution and electrochromic material.

\section{BIBLIOGRAPHY}

(1) M.A.Petit and V. Plichon, to be published.

(2) M. Bardin, P. Loheac, V. Plichon and N. Richard, to be published.

(3) B. E. Conway, J. Electrchem. Soc. 138, 1539 (1991).

(4) V. Plichon and S. Besbes, J. Electroanal. Chem., 284, 141 (1990). 

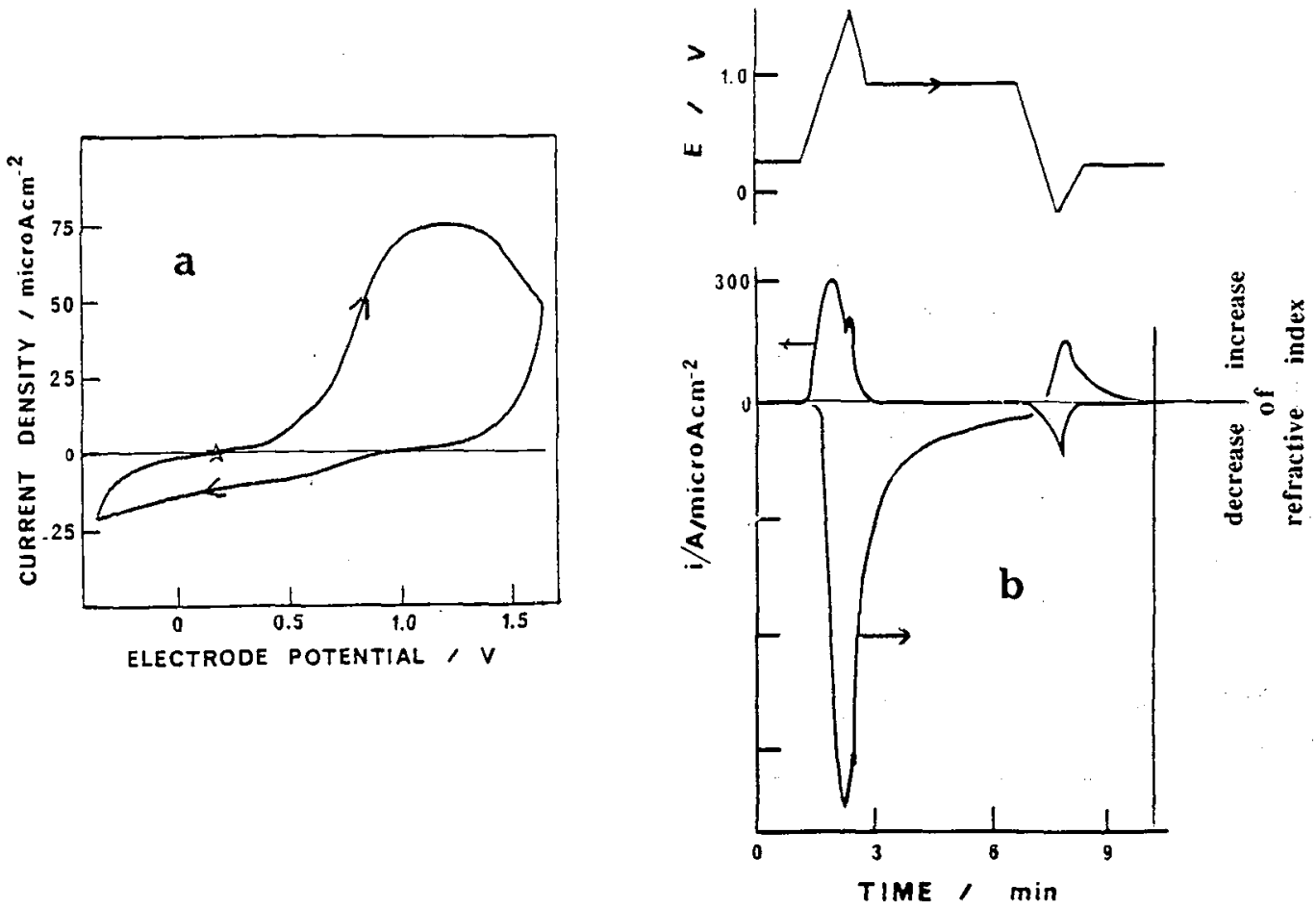

Figure 1. Sputtered iridium oxide film in $0.3 \mathrm{M} \mathrm{LiBF}_{4}$ in dry propylene carbonate.

a : cyclic voltamogram $(5 \mathrm{mV} / \mathrm{s}) \mathrm{b}:$ curves vs time $: \rightarrow$ potential profile $(20 \mathrm{mV} / \mathrm{s})$ -.. - current and — mirage deflection.
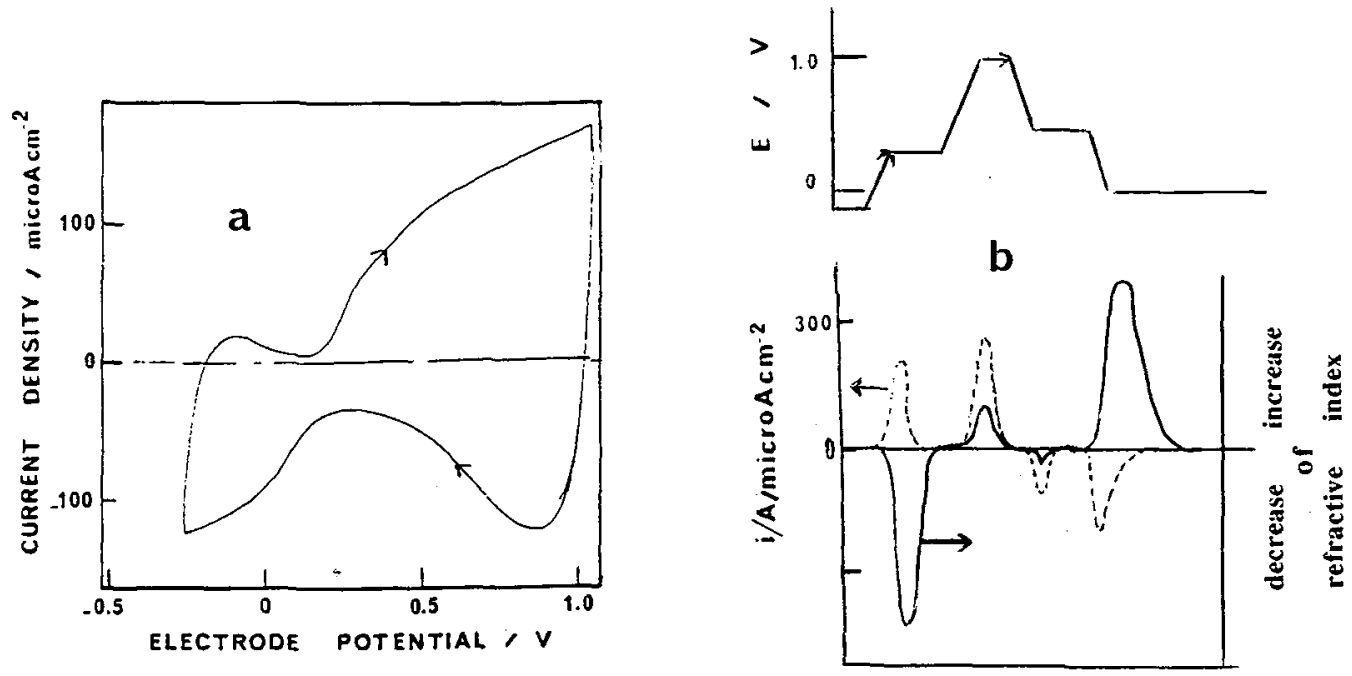

Figure 2. Sputtered iridium oxide films in $0.3 \mathrm{M} \mathrm{LiCF}_{3} \mathrm{SO}_{3}$ in water.

a : cyclic voltamogram $(5 \mathrm{mV} / \mathrm{s})$ b : curves vs time $: \rightarrow$ potential profile $(20 \mathrm{mV} / \mathrm{s})$ .... current and - mirage deflection. 

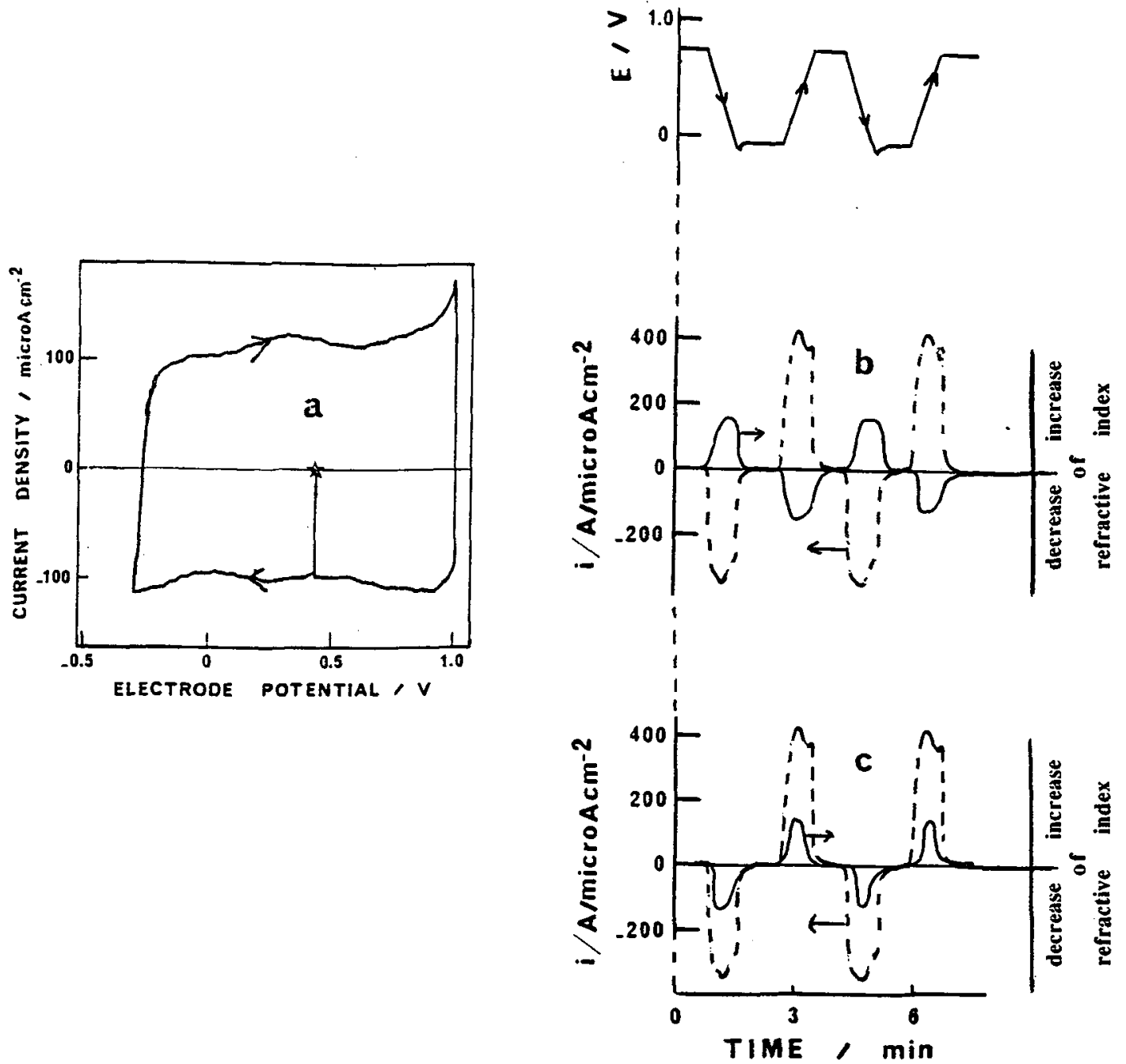

Figure 3. Sputtered iridium oxide films in $0.3 \mathrm{M} \mathrm{HCl}$ or LiBF4 in water.

a : cyclic voltamogram $(5 \mathrm{mV} / \mathrm{s}) \mathrm{b}: \rightarrow$ potential profile $(20 \mathrm{mV} / \mathrm{s})$ c (LiBF4) and d (HCl): - - - current and ___ mirage deflection curves vs time. 